\title{
Relationship of Anti-interleukin-6 Receptor Antibody to Interleukin-6 Level and Inducible Nitrite Oxide Levels in Peripheral Nerve Injury in Chronic Constriction Injury-Induced Rats: A Case-Control Study in Indonesia
}

\author{
Riki Sukiandra**iD, Eti Yerizel ${ }^{2}$, Yuliarni Syafrita ${ }^{3}$, Eriyati Darwin ${ }^{4}$ \\ ${ }^{1}$ Doctoral Student, Postgraduate Biomedical Science Program, Faculty of Medicine, Universitas Andalas, Padang, Indonesia; \\ ${ }^{2}$ Department of Biochemistry, Faculty of Medicine, Universitas Andalas, Padang, Indonesia; ${ }^{3}$ Department of Neurology, Faculty \\ of Medicine, Universitas Andalas, Padang, Indonesia; ${ }^{4}$ Department of Histology, Faculty of Medicine, Universitas Andalas, \\ Padang, Indonesia
}

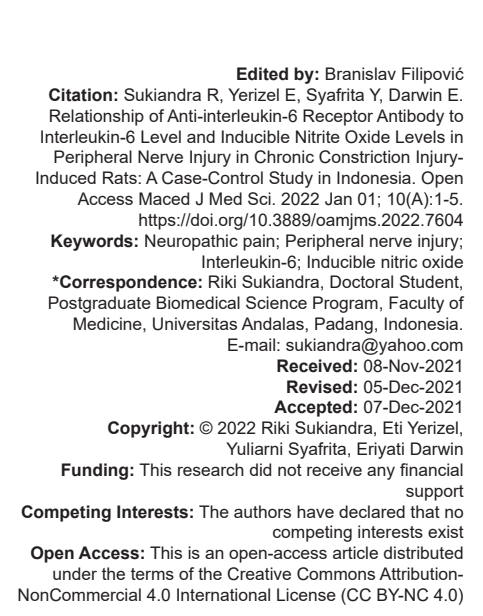

Abstract

BACKGROUND: Interleukin-6 (IL-6) and inducible Nitric oxide Synthase (iNOS) have an effect on neuropathic pain in the inflammatory process in peripheral nerve injuries.

AIM: This study aims to examine the effect of anti-IL-6 receptor antibody on IL-6 and iNOS levels as a consideration for the treatment of neuropathic pain in a rat model of peripheral nerve injury.

METHODS: Twenty-eight young adult male Wistar rats were treated for peripheral nerve injury and then divided into two groups. Fourteen treatment groups (Group P) were given anti-IL-6 receptor antibody by injection at a dose of $100 \mathrm{~g} /$ day by injection into the saphenous vein in the rat's leg for 3 days. In both groups, the serum IL-6 and iNOS levels were assessed on the $3^{\text {rd }}$ day after administration of anti-IL- 6 receptor antibody in group $P$, using the sandwich ELISA method.

RESULTS: The results showed that the administration of anti-IL-6 receptor antibody did not have a significant effect on reducing IL-6 and iNOS levels in group P ( $p>0.05)$. Administration of anti-IL-6 receptor antibody had more effect on IL-6 levels on iNOS levels, where a decrease in IL-6 levels caused a decrease in iNOS levels in group P $(p=$ 0.004 and $r=0.693)$.

CONCLUSIONS: We conclude that the present administration of anti-IL-6 receptor antibody cannot be considered as a treatment for neuropathic pain in peripheral nerve injuries, but can be used to influence IL-6 levels on iNOS levels.

\section{Introduction}

Pain is one of the complaints that make patients decide to seek treatment. Pain, according to the International Association for the Study of Pain (IASP), is an unpleasant subjective sensory and emotional experience that can be associated with actual tissue damage, potentially damaged, or describe the condition of the occurrence of damage [1], [2].

Pain is divided into nociceptive, neuropathic, and dysfunctional pain [3]. Neuropathic pain is a problem in the health sector, because it is the type of chronic pain that the most often causes disability in patients. Europe and America note that the prevalence of chronic pain is $15 \%$ of the adult population. Developing countries such as Indonesia, India, Nepal, and the Philippines have a prevalence of around $18.5 \%$. More than $35 \%$ of people who suffer from chronic pain can interfere with daily activities and cannot work for at least 3 years due to the pain they suffer [4]. Neuropathic pain is more resistant to general analgesic treatment and is a longterm problem for patients [5], [6], [7], [8], [9], [10].

Neuropathic pain is defined as pain associated with injury and/or dysfunction of the central or peripheral nervous system or changes in stimuli to these structures. The pathophysiology of neuropathic pain is complex and not fully understood. Neuropathic pain can arise from injury to the sciatic nerve [3]. Inducible Nitric Oxide Synthase (iNOS) plays a role in the inflammatory reaction that will later progress to neuropathic pain. Nitric oxide (NO) is a signaling molecule with immunomodulatory abilities. Macrophages are important cells in the inflammatory response, and have the ability to produce NO through the iNOS synthesis pathway in response to inflammatory stimuli. The high levels of NO can increase the cytotoxicity of inflammatory foci, and inhibit the expression and enzymatic activity of iNOS which exhibits anti-inflammatory effects [11]. NO is one of the cytotoxic molecules targeted to destroy 
pathogens and cancer cells. However, in autoimmune reactions and other forms of chronic inflammation, NO and NO derivatives can harm host tissues. In addition, $\mathrm{NO}$ regulates many vascular and cellular responses to inflammatory reactions. NOS blockers, particularly iNOS, have been described as having anti-inflammatory properties in various inflammatory reaction studies. Therefore, inhibitors of iNOS expression are attractive target molecules as anti-inflammatory components [11].

There is also convincing evidence that a third of the proinflammatory cytokine, interleukin-6 (IL-6) is involved in the mechanism of neuropathic pain after chronic constriction injury $(\mathrm{CCl})$ and peripheral nerve lesion [12]. Cytokine IL-6 is a dangerous proinflammatory mediator after peripheral nerve injury [13]. Various studies have shown that neuronal inflammation plays an important role in the pathological development of pain (Baron, 2006). Activation of kinase and signal transduction pathways and activator of transcriptional signaling pathway 3 (JAK-STAT3) through IL-6 are an important mechanism for signal transduction from the cell surface and are strongly associated with immunity and inflammatory reactions [13], [14]. Early activation of the pathway occurs frequently in spinal cord microglia and contributes to the development of neuropathic pain [15], [16], [17].

Therefore, IL-6 activity is an attractive therapeutic strategy in reducing neurologic deficits associated with peripheral nerve injury. In 2013, Murakami et al. reported that there was a beneficial effect of anti-IL-6 receptor antibody (MR16-1) on neuropathic pain in rats with spinal cord injury (SCI) [18]. However, to date, no studies have focused on the use of anti-inflammatory reagents to reduce neuropathic pain in peripheral nerve injuries. Therefore, through this study, researcher wanted to investigate the effect of administration of anti-interleukin- 6 receptor antibody on IL-6 and iNOS levels in peripheral nerve injury.

\section{Materials and Methods}

\section{procedure \\ Peripheral nerve injury modeling}

The surgical procedure was started by shaving the rat hair in the lumbar area until clean, cleaned with cotton and detergent solution, smeared with $70 \%$ alcohol, then smeared with enough povidone iodine. Then, the rats were given intraperitoneal injection of anesthetic in the form of ketamine at a dose $(100 \mathrm{mg} / \mathrm{kg})$. After anesthesia, the incision was made longitudinally parallel to the vertebra $1.5 \mathrm{~cm}$ long made $0.5 \mathrm{~cm}$ below the pelvis. The biceps femoris and gluteus superficialis muscles were separated, the sciatic nerve was seen, and then four were isolated and ligated using 4-0 chromic catgut sutures, each ligation separated by $1 \mathrm{~mm}$. Furthermore, the wound is closed layer by layer until the skin. The skin is stapled using leather staples to prevent the skin from opening due to being bitten by a rat. Topical antibiotics are applied to prevent infection in the surgical wound. Allodynia behavior, hyperalgesia, and spontaneous pain will appear after surgery.

\section{Randomization procedure}

After making the $\mathrm{CCl}$ model, all experimental animals with treatment (28 tails) were put into cages. Simple random sampling was carried out by randomly taking experimental animals one by one with their eyes closed which were put in a new cage as a treatment group in the form of giving anti-IL-6 receptor antibody (group P) until a total of 14 individuals were reached. While the remaining 14 experimental animals in the previous cage were the control group (group K).

\section{The procedure for administering anti-IL-6} receptor antibodies to the $P$ group

After randomization of the treatment groups, anti-IL-6 receptor antibodies were administered to group P. The action was carried out by giving anti-IL-6 receptor antibody at a dose of $100 \mathrm{~g} /$ day by injection into the saphenous vein in the legs of Wistar rats for 3 days using a syringe and a $25 \mathrm{G}$ venous catheter.

\section{Measurement of serum IL-6 levels and iNOS levels}

In both groups, serum IL-6 and iNOS levels were assessed on the $3^{\text {rd }}$ day after administration of anti-IL-6 receptor antibody in group P, using the sandwich ELISA method. Measurement of IL-6 levels using the rat IL-6 ELISA kit, and measurement of iNOS levels using the rat inducible NO synthase ELISA kit. Microwells were prepared and washed twice with wash buffer solution. Pipette each standard solution as much as $100 \mathrm{~L}$ and put into each microwell well. Next, $100 \mathrm{~L}$ of the sample solution was pipetted and put into another well. Biotin-conjugate solution was added to all wells. The microwell was covered with adhesive film and incubated at room temperature for $2 \mathrm{~h}$. The contents of the microwell were discarded and washed with wash buffer. This washing process was carried out 3 times. Streptavidin-HRP solution was added to each well as much as $100 \mathrm{~L}$ then, incubated at room temperature for $1 \mathrm{~h}$. The contents of the microwell liquid were discarded again and washed with the solution as well as 3 times. In each well, $100 \mathrm{~L}$ of tetramethylbenzidine substrate solution was added and incubated at room temperature for $10 \mathrm{~min}$. After $10 \mathrm{~min}, 100 \mathrm{~L}$ of stop solution was added to each well. Furthermore, the absorbance value of each solution in the microwell was determined at a wavelength of $450 \mathrm{~nm}$. 


\section{Statistical analysis of the data}

Test the normality of the data using Shapiro-Wilk because the number of samples is small (less than 50 ). $p>0.05$ indicates that the data are normally distributed. Comparative test to determine the difference in levels of iNOS and IL-6 levels in the two treatment groups using independent t-test for data with normal distribution or Mann-Whitney for data with abnormal distribution. $p<0.05$ is considered as statistically significant result.

\section{Results}

\section{IL-6 levels}

In this study, it was found that there was no statistical difference between the treatment group and the control group. There is only a tendency for the higher scores to be found in the treatment group (Table 1).

Table 1: Comparative results of anti-IL-6 receptor antibody administration on IL-6 levels in both groups

\begin{tabular}{llll}
\hline Samples & $\mathrm{n}$ & Median (min.-max.) & $\mathrm{p}$ \\
\hline P group & 15 & $10,6(5,9-13,3)$ & 0,093 \\
K group & 15 & $9,7(7,0-14,2)$ & \\
\hline
\end{tabular}

\section{Inducible NO synthase (iNOS) levels}

In the assessment of iNOS levels, the researchers also did not find any specific differences between the groups given anti-IL- 6 receptor antibodies and the untreated group ( $p>0.05)$ (Table 2).

Table 2: Comparative results of anti-IL-6 receptor antibody administration on iNOS levels in both groups

\begin{tabular}{llll}
\hline Samples & $\mathrm{n}$ & Median (min.-max.) & $\mathrm{p}$ \\
\hline P group & 15 & $96.8(55.9-114.5)$ & 0.548 \\
K group & 15 & $98.7(76.8-110.6)$ & \\
\hline
\end{tabular}

\section{Correlation of IL-6 levels and iNOS levels}

Researchers tried to see the relationship between increased levels of IL-6 and levels of iNos in both groups after peripheral nerve injury. In group $P$, there was a significant correlation between IL-6 levels and iNOS levels (Table 3).

Table 3: Correlation test of IL-6 levels and iNOS levels in the $P$ group

\begin{tabular}{lll}
\hline Variable & Statistic & iNOS Levels \\
\hline IL-6 Levels & $\mathrm{R}$ & 0.693 \\
& $\mathrm{P}$ & 0.004 \\
& $\mathrm{~N}$ & 15 \\
\hline
\end{tabular}

From the results above, it shows that there is a significant correlation between IL-6 levels and iNOS levels in group $\mathrm{P}$. These results also indicate a positive correlation direction with a strong correlation strength $(r=0.693)$. Meanwhile, it is known that there is no significant correlation between IL-6 levels and iNOS levels in group $\mathrm{K}(\mathrm{p}>0.05)$ (Table 4).
Table 4: Correlation test for IL-6 levels and iNOS levels in the $\mathrm{K}$ group

\begin{tabular}{lll}
\hline Variable & Statistic & iNOS Levels \\
\hline IL-6 Levels & $\mathrm{R}$ & 0,439 \\
& $\mathrm{P}$ & 0,101 \\
& $\mathrm{~N}$ & 15 \\
\hline
\end{tabular}

\section{Discussion}

There are studies reporting that there is a beneficial effect of anti-interleukin-6 (IL-6) receptor antibody (MR16-1) on neuropathic pain in rats with SCI. IL-6 was significantly significant in the treatment group within 24 and 72 h after trauma [18]. Previously, there were no studies aimed at examining the effect of anti-IL-6 receptor antibodies on IL-6 and iNOS levels in rats with peripheral nerve injury.

This study used rats with peripheral nerve injury, and the results showed that there was no significant difference in the results of IL-6 levels and iNOS levels in the group that received anti-IL-6 receptor antibody treatment with the control group. This result is in contrast to the previous studies which stated that intrathecal injection of anti-IL-6 can neutralize antibodies that affect pain (Li, 1999).

In addition to IL-6, inducible NO synthase (iNOS) also plays a role in inflammatory reactions that will later progress to neuropathic pain. NO production and iNOS expression have been shown to be increased in many inflammatory diseases [19], [20]. So far, there have been no studies discussing the effect of anti-IL-6 receptor antibodies on increasing iNOS levels in peripheral nerve injuries.

In this study, this was done and the results showed that there was no significant difference in iNOS levels to the administration of anti-IL-6 receptor antibodies in cases of peripheral nerve injury. This can be a reference for further research to further assess the effect of anti-IL-6 receptor antibodies on IL-6 levels and iNOS levels in cases of peripheral nerve injury.

In this study, the researchers also looked at the relationship between IL-6 levels and iNOS levels in the two groups. After peripheral nerve injury, pro- and anti-inflammatory cytokines are produced by immune and non-immune cells that reside distal to the injured nerve or are recruited from the blood circulation [21], [22]. Researchers found that there was a significant relationship to IL-6 and iNOS levels in the group with anti-IL-6 receptor antibody. This indicates that the administration of anti-IL-6 receptor antibodies will cause IL-6 levels and iNOS levels to increase or decrease simultaneously.

This can be considered for further research to see in more detail the effect of anti-IL-6 receptor antibodies on IL-6 levels and iNOS levels in peripheral nerve injuries. So far, there have been no studies showing the effect of anti-IL-6 receptor antibodies 
on IL-6 levels and iNOS levels in peripheral nerve injuries.

\section{Conclusions}

Based on this study, administration of anti-IL-6 receptor antibody to IL-6 and iNOS levels did not have a significant effect on cases of peripheral nerve injury. The administration of anti-IL-6 receptor antibody has more effect on changes in IL-6 levels with iNOS, where indirectly, the decrease in IL-6 levels in the administration of anti-IL-6 receptor antibodies can also cause a decrease in iNOS. Hence, the researchers concluded that the use of anti-IL-6 receptor antibodies for now cannot be applied as therapy in cases of peripheral nerve injury. However, further research can be considered with a larger number of samples.

\section{Authors' Contributions}

The experiments conceived and designed by RS, EY, YS, and ED. RS performed the experiments and analyzed the data. All authors contributed the reagents/materials/analysis tools. All authors read and approved the final manuscript.

\section{References}

1. Nicholson B. Differential diagnosis: Nociceptive and neuropathic pain. Am J Manag Care. 2006;12 Suppl 9:S256-62. PMid:16774457

2. Borda AP, Sonnek FC, Fonteyne V, Papaioannou EG. Guidelines on Pain Management and Palliative Care. Arnhem, Netherlands: European Association of Urology; 2013. p. 70.

3. Akkurt HE, Gümüs H, Göksu H, Odaba OF, Yilmaz H. Gabapentin treatment for neuropathic pain in a child with sciatic nerve injury. Case Rep Med. 2015;2015:873157.

4. McMahon SB, Malcangio M. Current challenges in glia-pain biology. Neuron. 2009;64(1):46-54. https://doi.org/10.1016/j. neuron.2009.09.033

PMid:19840548

5. McCarberg BH, Billington R. Consequences of neuropathic pain: Quality-of-life issues and associated costs. Am J Manag Care. 2006;12 Suppl 9:S263-8.

PMid:16774458

6. Childers WE Jr., Baudy RB. N-methyl-D-aspartate antagonists and neuropathic pain: The search for relief. J Med Chem. 2007;50(11):2557-62. https://doi.org/10.10a/jm060728b PMid:17489572
7. Inoue $\mathrm{K}$, Tsuda $\mathrm{M}$. Microglia and neuropathic pain. Glia. 2009;57(14):1469-79. https://doi.org/10.1002/glia.20871 PMid:19306358

8. Milligan ED, Watkins LR. Pathological and protective roles of glia in chronic pain. Nat Rev Neurosci. 2009;10(1):23-36. https://doi.org/10.1038/nrn2533

PMid:19096368

9. Zhuo M. A synaptic model for pain: Long-term potentiation in the anterior cingulate cortex. Mol Cells. 2007;23(3):259-71. PMid: 17646700

10. Kandel ER. The molecular biology of memory storage: A dialogue between genes and synapses. Science. 2001;294(5544):1030-8. https://doi.org/10.1126/science.1067020 PMid: 11691980

11. Vallance P, Leiper J. Blocking no synthesis: How, where and why? Nat Rev Drug Discov. 2002;1(12):939-50. https://doi. org/10.1038/nrd960

PMid: 12461516

12. Zhang W, Liu LY, Xu TL. Reduced potassium-chloride co-transporter expression in spinal cord dorsal horn neurons contributes to inflammatory pain hypersensitivity in rats. Neuroscience. 2008;152(2):502-10. https://doi.org/10.1016/j. neuroscience.2007.12.037 PMid: 18262726

13. Li P, Wilding TJ, Kim SJ, Calejesan AA, Huettner JE, Zhuo M. Kainate-receptor-mediated sensory synaptic transmission in mammalian spinal cord. Nature. 1999;397(6715):161-4. https:// doi.org/10.1038/16469

PMid:9923678

14. Wu LJ, Zhuo M. Targeting the NMDA receptor subunit NR2B for the treatment of neuropathic pain. Neurotherapeutics. 2009;6(4):693-702. https://doi.org/10.1016/j.nurt.2009.07.008 PMid:19789073

15. Ji RR, Kohno T, Moore KA, Woolf CJ. Central sensitization and LTP: Do pain and memory share similar mechanisms? Trends Neurosci. 2003;26(12):696-705. https://doi.org/10.1016/j. tins.2003.09.017 PMid: 14624855

16. Ikeda H, Heinke B, Ruscheweyh R, Sandkuhler J. Synaptic plasticity in spinal lamina I projection neurons that mediate hyperalgesia. Science. 2003;299(5610):1237-40. https://doi. org/10.1126/science.1080659 PMid:12595694

17. Sandkuhler J. Understanding LTP in pain pathways. Mol Pain. 2007;3:9. https://doi.org/10.1186/1744-8069-3-9. PMid: 17407590

18. Murakami A, Kanchiku T. Anti-interleukin-6 receptor antibody reduces neuropathic pain following spinal cord injury in mice. Exp Ther Med. 2013;6(5):1194-8. https://doi.org/10.3892/ etm.2013.1296 PMid:24223643

19. Kolios G, Brown Z, Robson RL, Robertson DA, Westwick J. Inducible nitric oxide synthase activity and expression in a human colonic epithelial cell line, HT-29. $\mathrm{Br} J$ Pharmacol. 1995;116(7):2866-72. https://doi.org/10.1111/j.1476-5381.1995. tb15938.x PMid:8680718

20. Amin B, Hosseinzadeh $\mathrm{H}$. Evaluation of aqueous and ethanolic extracts of saffron, Crocus sativus L., and its constituents, safranal and crocin in allodynia and hyperalgesia induced by chronic constriction injury model of neuropathic pain in rats. Fitoterapia. 2012;83(5):888-95. https://doi.org/10.1016/j. fitote.2012.03.022 


\section{PMid:22484092}

21. Bhardwaj HC, Muthuraman A, Hari KS, Navis S. Antioxidative and anti-inflammatory potentials of ambroxol in ameliorating vincristine induced peripheral neuropathic pain in rats. J Neuroinfect Dis. 2016;7:202.
22. Fregnan F, Muratori L, Simões AR, Giacobini-Robecchi MG, Raimondo S. Role of inflammatory cytokines in peripheral nerve injury. Neural Regen Res. 2012;7(29):2259-66. https://doi. org/10.3969/j.issn.1673-5374.2012.29.003

PMid:25538747 